\title{
Apolipoprotein E: a review of its roles in lipoprotein metabolism, neuronal growth and repair and as a risk factor for Alzheimer's disease $^{1}$
}

Apolipoprotein E (Apo E) is a polymorphic secretory glycoprotein expressed by a wide variety of tissues in mammals, particularly the liver and the brain (Mahley, 1988). Apo E recently attracted considerable attention when it was found that one of its alleles, apo E4, was associated with an increased risk for Alzheimer's disease (Strittmatter et al. 1993a). This protein has been well studied with respect to its roles in lipoprotein metabolism in the peripheral circulation and in the nervous system. Accordingly, this protein's structure and function will be reviewed in order to place the potential roles of apo $\mathrm{E}$ in Alzheimer's disease into perspective.

\section{APO E PLAYS A CRITICAL ROLE IN LIPOPROTEIN METABOLISM}

Lipids, including triglycerides, cholesterol and phospholipids, are relatively insoluble in aqueous medium. These substances must, therefore, be packed into lipoprotein particles for transport in the blood. Lipoproteins are spherical and have a common structural organization: a hydrophobic core consisting of cholesterol esters and triglycerides and a more hydrophilic shell consisting of phospholipids, unesterified cholesterol and apolipoproteins that are orientated with their hydrophilic domains towards the outside (reviewed by Havel \& Kane, 1989).

Lipids are transported in the blood by different lipoprotein pathways (Mahley, 1988), as follows.

(1) Dietary lipids are packed into large lipoprotein particles, called chylomicrons, which are secreted into the lymph. These enter the circulation via the thoracic duct. The enzyme lipoprotein lipase, found in the vascular endothelium, hydrolyses triglycerides from the core of these particles to yield free fatty acids that are taken up primarily by adipocytes. The resultant denser, smaller, chylomicron remnants can be removed from the circulation by specific chylomicron remnant receptors on the liver cells. Apo E serves as the ligand on these particles that is recognized by the receptors.

(2) Endogenously produced lipoproteins secreted by the liver are known as very low density lipoproteins (VLDL). These are also hydrolysed by lipoprotein lipase to yield smaller intermediate density lipoproteins (IDL). IDL can undergo two fates. First, they can be removed directly from the circulation by low density lipoprotein (LDL) receptors on liver cells. Again, apo E serves as the ligand for the recognition of IDL by these receptors. Alternatively, IDL can be further hydrolysed to yield even smaller and denser particles called low density lipoproteins (LDL). LDL are removed from the circulation by LDL receptors. Apo B-100, the sole apolipoprotein found on these particles, serves as the ligand for receptor-recognition in this case.

(3) In a third pathway, a class of lipoproteins known as high density lipoproteins (HDL) absorb cholesterol from cholesterol-laden peripheral tissues, like the vascular endothelium. Some HDL contain apo E. These particles can be removed from the circulation by hepatic LDL receptors. The liver is a particularly important organ in cholesterol homeostasis as it is the major route for cholesterol excretion, which occurs in the bile.

\footnotetext{
1 Address for correspondence: Dr David C. Rubinsztein, East Anglian Genetics Service, Molecular Genetics Laboratory, Box 158, Addenbrooke's NHS Trust, Hills Road, Cambridge CB2 2QQ.
} 
Apo $\mathrm{E}$ exists in humans in three functionally distinct allelic isoforms (apo E2, apo E3 and apo E4) that are encoded at a single locus on the long-arm of chromosome 19 (Mahley, 1988). The frequencies of these alleles vary between populations and according to age. However, in all populations, the frequency of the apo E3 allele is greater than $60 \%$ (Davignon et al. 1988). These isoforms are distinguishable by base substitutions at codons 112 and 158 . Apo E3 has a cysteine at codon 112 and an arginine at codon 158. Apo E2 has cysteines at both codons and has a markedly reduced affinity for its receptors relative to apo E3. Individuals who are homozygous for apo E2 show impaired clearance rates of dietary derived lipoproteins. In most cases, these individuals have advantageously reduced serum LDL-cholesterol concentrations. This is thought to be due to comparative up-regulation of their LDL receptors resulting from the relatively decreased flux of dietary-derived lipid entering their hepatocytes. This leads to increased clearance of LDL, which are recognized by receptors by their sole apolipoprotein, apo B-100. However, about $2 \%$ of apo E2 homozygotes develop Type III hyperlipidaemia. This is generally associated with other metabolic abnormalities like alcoholism and diabetes. Apo E4, the ancestral isoform (Hanlon \& Rubinsztein, 1995), has arginines at both codons 112 and 158. This isoform binds normally to its receptors but associates with dietary-derived lipoproteins more avidly than apo E3, resulting in increased clearance of apo E4-containing lipoproteins and down-regulation of the LDL receptors. Thus, LDL-cholesterol concentrations in apo E4 homozygotes are higher than those in apo E3 homozygotes. These allele-specific effects on lipoprotein metabolism suggest that apo E mediates rate-limiting steps in lipoprotein metabolism (Weintraub et al. 1987; Mahley, 1988). This suggestion is further supported by observations in the very rare humans who are apo E-deficient. Such people present with Type III hyperlipidaemia and xanthomata. Similarly, transgenic apo E-deficient mice develop severe hypercholesterolaemia and atherosclerosis (Plump et al. 1992).

\section{STRUCTURE-FUNCTION RELATIONSHIPS OF THE APO E PROTEIN}

Knowledge of the structure-function relationships of apo $E$ is important to allow an understanding of its potential role in Alzheimer's disease. The mature apo E protein consists of 299 amino acids. Amino acids 1-183 are sufficient for normal apo $\mathrm{E}$ binding to the LDL receptor. More detailed studies revealed that amino acids 130-150, which form an $\alpha$-helix, constitute the LDL receptorbinding domain. This region contains many basic amino acids that are thought to interact with the acidic residues in the ligand-binding domain of the LDL receptor. The substitution of cysteine for arginine at codon 158 (the change that decreases the binding of apo E2 relative to apo E3) is thought to disrupt the conformation of this $\alpha$-helix. Apo E4 binds to the LDL receptor with a similar affinity to apo E3. However, apo E4 associates preferentially with VLDL compared with HDL, relative to apo E3. The carboxy-terminal region of apo E contains what is thought to be the lipid-binding domain. This region is a strong amphipathic $\alpha$-helical structure that has one polar side and a nonpolar lipid-binding side (Mahley et al. 1990). Model building based on the crystal structure of apo E3 suggested that the arginine at codon 112 of apo E4 (compared with a cysteine at this position in apo E3) may disrupt specific interactions between the amino- and carboxy-termini of this protein and alter its lipid-binding determinants (Wilson et al. 1991).

\section{APO E IN THE NERVOUS SYSTEM}

The brain produces about $20 \%$ of the body's apo $\mathrm{E}$ and this protein is a major component of the cerebro-spinal fluid (4-5\%) (Mahley, 1988). Apo E is synthesized both in the central nervous system (by astrocytes ad macrophages) and in the peripheral nervous system (by glial cells associated with neuron cell bodies and non-myelinating Schwann cells) (Boyles et al. 1985, 1989). In the peripheral and central nervous systems apo $\mathrm{E}$ is thought to play a role in the response to injury. Following peripheral nerve injury apo E levels rise 250-fold (Boyles et al. 1990). After nerve damage, while the axon dies and the Schwann cells absorb myelin, local macrophages and monocyte-derived 
macrophages (from the peripheral circulation) produce large amounts of apo E distal to the injury site. Droplets of cholesterol stored by macrophages and Schwann cells during this phase of nerve degeneration are used later when the nerve regenerates. As axons regenerate in the first week following injury, their tips express increased numbers of LDL receptors (presumably in an attempt to obtain additional exogenous cholesterol). After axonal regeneration, apo E accumulates distal to the injury site and macrophages become increasingly laden with cholesterol. As remyelination starts 3 weeks after injury, the Schwann cells exhaust their cholesterol stores and also start to express increased numbers of LDL receptors. Over the next few weeks the macrophages start to lose their cholesterol and apo $\mathrm{E}$ is found in the extra-cellular matrix as a component of cholesterol-laden lipoproteins. This temporal relationship between apo E secretion and LDL receptor up-regulation after nerve injury suggests that receptor-mediated uptake of lipoprotein particles via apo $\mathrm{E}$ is playing a role in cholesterol acquisition by the regenerating nerve (Boyles et al. 1989). It is, however, possible that the presence of apo $E$ is not rate-limiting for peripheral nerve regeneration after injury, since transgenic apo E-deficient mice seem to repair nerve injury as well as mice that express apo $E$ in the 4 weeks after the insult. It has been suggested that other apolipoproteins, like apo D, may substitute for apo $\mathrm{E}$ in its role in nerve repair in these mice (Popko et al. 1993).

Similar increases in apo E expression occur after central nervous system injury (to spinal cord and optic nerve) (Skene \& Shooter, 1983) and the temporal pattern of apo E expression after entorhinal cortex lesioning suggests that apo E plays a role in reactive synaptogenesis (Poirier et al. 1991). Similarly, apo E mRNA and protein levels are also increased in Alzheimer's disease and in the brains of scrapie-infected mice (Diedrich et al. 1991). Low levels of apo E and LDL receptors (Swanson et al. 1988) are expressed constitutively in the central nervous system and it is thus possible that these proteins are continuously involved in maintenance.

Apo $\mathrm{E}$ is also thought to play a role in nerve growth. In experiments where rabbit dorsal root ganglion cells were cultured in lipoprotein-containing medium in vitro, the addition of apo $\mathrm{E}$ had clear effects by decreasing neurite branching and increasing the extent of neurite extension from the cell body (Handelmann et al. 1992). Recent experiments have shown isoform-specific effects in this type of experimental system: apo E3 increased neurite outgrowth, while apo E4 decreased outgrowth. These effects seem to be mediated by lipoprotein receptors (Nathan et al. 1994).

Apo $\mathrm{E}$ has also been postulated to play a role in immunoregulation, as apo E-containing lipoproteins and LDL can either stimulate or inhibit antigen- or mitogen-induced $\mathrm{T}$ lymphocyte activation and proliferation. These effects seem to be the result of these lipoproteins binding to the LDL receptor (stimulation) and the so-called immunosuppressive receptor (inhibition) (Mahley, 1988).

\section{APO E4: A RISK FACTOR FOR ALZHEIMER'S DISEASE}

Alzheimer's disease (AD) has been classified into early-onset $v$. late-onset disease. The age of onset used as an arbitrary cut-off between early- and late-onset disease is either 60 or 65 . Familial AD is genetically heterogeneous. About 5-10\% of early-onset kindreds can be accounted for by mutations of the amyloid precursor protein. Most other early-onset cases result from mutations at an as yet uncharacterized locus on chromosome 14. However, neither of these loci seems to have a major effect in late-onset AD (reviewed by Mullan \& Crawford, 1993).

The long-arm of chromosome 19 was first implicated in late-onset AD in 1987 (Schellenberg et al. 1987), when an association was found between familial AD and an allele at the polymorphic apo CII locus. This study was subsequently confirmed (Pericak-Vance et al. 1991, Schellenberg et al. 1992). In late 1993, Strittmatter and colleagues reported that the frequency of the apo E4 allele was increased in late-onset AD patients (50\%) compared with controls (16\%) (Strittmatter et al. 1993a). These results were not surprising, as the apo E and apo C II genes are part of a gene cluster and are only separated by $40 \mathrm{kB}$ (Houlston et al. 1989).

Subsequent studies have confirmed that both sporadic and familial late-onset AD are associated with the apo E4 allele (e.g. Corder et al. 1993; Chartier-Harlin et al. 1994). Individuals with one apo 
E4 allele have a three-fold increased risk of getting late-onset $A D$, compared with individuals with no apo E4 alleles, while apo E4/E4 homozygotes have more than an eight-fold increased risk (Corder et al. 1993). Indeed, it seems that the effect associated with the apo E4 allele is strong enough to result in $\mathrm{AD}$ in more than $80 \%$ of apo E4/E4 homozygotes by the age of 80 (Corder $e t$ al. 1993; Poirier et al. 1993).

Increasing dose of apo E4 was associated with an earlier age of onset of AD (Corder et al. 1993; Chartier-Harlin et al. 1994). For example, Corder and co-workers (1993) found that their late-onset AD patients with no apo E4 alleles had a mean age onset of 84.3 years, compared with those with one apo E4 allele who had a mean age of onset of 75.5 years and apo E4/E4 homozygotes who had a mean age of onset of 68.4 years. A similar trend was also found for age of death as a function of apo $\mathrm{E} 4$ dose (Corder et al. 1993).

The strong association between apo E4 dose and susceptibility to late-onset AD suggest either that the apo $\mathrm{E} 4$ gene is playing a causal role in the pathogenesis of $\mathrm{AD}$, or that apo $\mathrm{E} 4$ is in linkage disequilibrium with a pathogenic allele of a nearby gene. (This scenario would occur if a mutation occurred in a putative gene on a chromosome 19 associated with an apo E4 allele. Since linkage disequilibrium is destroyed by recombination, this putative gene would have to be close enough to apo $E$ to prevent a high recombination rate between the loci and the mutation would have to have occurred recently enough for the recombination between the putative locus and apo E4 not to have resulted over time in a significant number of mutations being associated with apo E3 and E2 alleles.) However, late onset $\mathrm{AD}$ does occur in individuals who do not have apo E4 alleles. Therefore, if apo $\mathrm{E} 4$ is the causative locus, then late-onset $\mathrm{AD}$ is either polygenic (where apo $\mathrm{E} 4$ is associated with a major effect), and/or late-onset $\mathrm{AD}$ is genetically heterogeneous. These possibilities have not been resolved. However, a number of recent findings have allowed further characterization of the association of apo E4 in this disease. Apo E4 has emerged as a risk factor for early-onset AD (Chartier-Harlin et al. 1994; Okuizumi et al. 1994; van Duijn et al. 1994). In addition, there have been suggestions that there is a gene-gene interaction between the apo $\mathrm{E}$ and the amyloid precursor protein (APP) loci, whereby the presence of the apo E4 decreases the age of onset of symptoms in patients with APP mutations (Alzheimer's Disease Collaborative Group, 1993; St George-Hyslop et al. 1994). These results are consistent with the possibility that late-onset $\mathrm{AD}$ is polygenic where apo E4 (or a linked gene) modifies the severity of another mutation(s).

Recent results suggest that the apo $\mathrm{E} 2$ allele is associated with a protective effect in late-onset $\mathrm{AD}$ (Chartier-Harlin et al. 1994; Corder et al. 1994; Rubinsztein et al. 1994). This protective effect was shown to be independent of the overrepresentation of the apo E4 allele in late-onset AD cases: when only apo E2 and apo E3 alleles were examined in late-onset AD patients and controls, there was a significant under-representation of the apo E2 allele relative to apo E3 in patients (Corder et al. 1994; Rubinsztein et al. 1994). Corder and co-workers (1994) have argued that these results strengthen the epidemiological evidence that apo $\mathrm{E}$ itself is playing a role in the pathogenesis in $\mathrm{AD}$. The alternative possibility would be the less attractive scenario that apo E4 was in linkage disequilibrium with a pathogenic allele of a nearby gene, while apo E2 was in linkage disequilibrium with a protective allele (presumably at the same locus) (Corder et al. 1994).

Apo E4 has also been associated with multi-infarct dementia (Shimano et al. 1989; Noguchi et al. 1993). In this disease it is likely that apo E4 is exerting a causal effect: apo E4 is associated with raised LDL-cholesterol levels (see above) and these are in turn associated with an increased predisposition to thrombosis. However, apo $\mathrm{E}$ genotypes do not seem to confer varying susceptibility risks in two other neurodegenerative diseases: Parkinson's disease and multiple sclerosis (Rubinsztein et al. 1994).

\section{POSSIBLE MECHANISMS WHEREBY APO E4 COULD CAUSE AD}

Although the evidence that apo $E$ is causally involved in the pathogenesis of $A D$ is not conclusive, various histological, physiological and biochemical studies have provided sufficient data for tantalizing models to have been proposed. 


\section{Apo $\mathrm{E}$ binds to $\beta$-amyloid}

One of the characteristic pathological features of $\mathrm{AD}$ is the deposition of $\beta$-amyloid as amyloid fibrils within senile plaques and blood vessels. $\beta$-amyloid results from abnormal cleavage of the amyloid precursor protein. However, $\beta$-amyloid may also be a normal constituent of cerebro-spinal fluid (Mullan \& Crawford, 1993). Apo E has been shown to associate with cerebral amyloid in a wide variety of amyloidoses including AD, Down's syndrome, Creutzfeldt-Jacob disease, and familial Mediterranean fever (Namba et al. 1991, Wisniewski \& Frangione, 1992). Wisniewski and coworkers (1993) showed that apo E binds with high avidity to $\beta$-amyloid and suggested that it may also bind to soluble $\beta$-amyloid. They postulated that apo $\mathrm{E}$ may act as a 'pathological chaperone' that binds to soluble $\beta$-amyloid and promotes conformational changes that lead to fibril formation possibly by reducing amyloid solubility (Wisnieski \& Frangione, 1992; Wisniewski et al. 1993). The high avidity binding of apo $\mathrm{E}$ to $\beta$-amyloid was confirmed by Strittmatter and colleagues (1993a) who later compared the binding of synthetic $\beta$-amyloid with purified apo E3 and apo E4. Both isoforms bound $\beta$-amyloid extremely avidly (but probably non-covalently) in a saturable fashion. Binding was enhanced in oxygenated buffer and involved residues $12-28$ of $\beta$-amyloid and residues 244-272 of apo E (i.e. the lipid-binding domain - see above). These experiments also revealed isoform-specific kinetics of binding: binding to apo E4 only required minutes of incubation compared with the hours needed for apo E3. In addition, apo E3 and apo E4 bound optimally to $\beta$-amyloid at different $\mathrm{pH}$ (Strittmatter et al. 1993b). The isoform-specific differences in apo $\mathrm{E}$ binding to $\beta$-amyloid were also reflected in autopsy studies of brain from patients with sporadic lateonset $\mathrm{AD}$ when a strong correlation was found between the number of apo E4 alleles and $\beta$-amyloid deposition (Schmechel et al. 1993).

Although these experiments are consistent with the possibility that apo E4 mediates its pathogenicity through binding to $\beta$-amyloid, this may be a secondary phenomenon. As mentioned earlier, apo E mRNA and protein expression are increased in AD (Diedrich et al. 1991). It is thus possible that the increased amyloid deposition in plaques in AD may be the consequence of the pathogenicity of apo E4 acting elsewhere, as opposed to being the primary cause of the disease. For example, an alternative possible mode of pathogenesis may involve receptor-mediated endocytosis of apo E- $\beta$-amyloid complexes followed by $\mathrm{pH}$-dependent dissociation in primary lysosomes, as binding of apo E4 to $\beta$-amyloid is more sensitive to $\mathrm{pH}$ changes than apo E3 (Strittmatter et al. $1993 b$ ). The possibility that apo $\mathrm{E}$ may be pathogenic intracellularly has been considered, as apo $E$ is associated with neurofibrillary tangles (Namba et al. 1991 ; Strittmatter et al. 1993 b) and many workers feel that the formation of neurofibrillary tangles reflects critical events in the pathogenesis of AD. Another hypothesis has been stimulated by the observation that apo E4 does not bind to the microtubule-associated protein tau, while apo E3 binds strongly (Strittmatter et al. 1994). The binding of tau to microtubules is thought to play a role in their stabilization. It is thought that abnormal phosphorylation of tau results in decreased binding to microtubules causing them to degenerate, ultimately leading to neuronal death. It has been postulated that apo E3 binding to tau prevents abnormal phosphorylation, while apo E4 is unable to perform this function (Strittmatter et al. 1994).

\section{CONCLUSION}

At present, it is clear that the apo E4 allele is associated with a dose-dependent risk for late-onset $\mathrm{AD}$. However, it has not been conclusively proved that apo E4, as opposed to a linked gene, is pathogenic. Further studies will need to be performed to explore the causal role of apo $\mathrm{E}$ in $\mathrm{AD}$. These may necessitate the use of transgenic animals expressing the different human apo $\mathrm{E}$ isoforms. Ultimately, an understanding of the nature of the contribution of this locus on chromosome 19 to the pathogenesis of $\mathrm{AD}$ will be of great value, as it will elucidate novel parts of the pathway(s) that lead to $\mathrm{AD}$ that may be accessible to therapy. 


\section{REFERENCES}

Alzheimer's Disease Collaborative Group (1993). Apo E genotype and Alzheimer's disease. Lancet 342, 737-738.

Boyles, J. K., Pitas, R. E., Wilson, E., Mahley, R. W. \& Taylor, J. M. (1985). Apolipoprotein $E$ associated with the astrocytic glia of the central nervous system and with nonmyelinating glia of the peripheral nervous system. Journal of Clinical Investigation 76, 1501-1513.

Boyles, J. K., Zoellner, C. D., Anderson, L. J., Kosik, L. M., Pitas, R. E., Weisgraber, K. H., Hui, D. Y., Mahley, R. W., GebickeHaerter, P. J., Ignatius, M. J. \& Shooter, E. M. (1989). A role for apolipoprotein E, apolipoprotein A-I, and low density lipoprotein receptors in cholesterol transport during regeneration and remyelination of the rat sciatic nerve. Journal of Clinical Investigation 83, 1015-1031.

Boyles, J. K., Notterpek, L. M. \& Anderson, L. J. (1990). Accumulation of apolipoproteins in the regenerating and remyelinating mammalian peripheral nerve. Journal of Biological Chemistry 265, 17805-17815.

Chartier-Harlin, M.-C., Parfitt, M., Legrain, S., Perez-Tur, J., Brousseau, T., Evans, A., Berr. C.. Vidal, O., Roques, P., Gourlet, V., Fruchart, J.-C., Delacourte, A., Rossor, M. \& Amouyel, P. (1994). Apoliprotein E, $\epsilon 4$ allele as a major risk factor for sporadic and late-onset forms of Alzheimer's disease: analysis of the 19q13.2 chromosomal region. Human Molecular Genetics 3, 569-574.

Corder, E. H., Saunders, A. M., Strittmatter, W. J., Schmechel, D. E., Gaskell, P. C., Small, G. W., Roses, A. D., Haines, J. L. \& Pericak-Vance, M. A. (1993). Gene dose of apolipoprotein E type 4 allele and the risk of Alzheimer's disease in late onset families. Science 261, 921-923.

Corder, E. H., Saunders, A. M., Risch, N. J., Strittmatter, W. J., Schmechel, D. E., Gaskell, P. C. Jr., Rimmler, J. B., Locke, P. A., Conneally, P. M., Schmader, K. E., Small, G. W., Roses, A. D., Haines, J. L. \& Pericak-Vance, M. A. (1994). Protective effect of apolipoprotein E type 2 allele for late onset Alzheimer disease. Nature Genetics 7, 180-184.

Davignon, J., Gregg, R. E. \& Sing, C. F. (1988). Apolipoprotein E polymorphism and atherosclerosis. Arteriosclerosis 8, 1-21.

Diedrich, J. F., Minnigan, H., Carp, R. I., Whitaker, J. N., Race, R., Frey, W. II \& Haase, A. T. (1991). Neuropathological changes in scrapie and Alzheimer's disease are associated with increased expression of apolipoprotein $\mathrm{E}$ and cathepsin $\mathrm{D}$ in astrocytes. Journal of Virology 65, 4759-4768.

Handelmann, G. E., Boyles, J. K., Weisgraber, K. H., Mahley, R. W. \& Pitas, R. E. (1992). Effects of apolipoprotein E, $\beta$-very low density lipoproteins, and cholesterol on the extension of neurites by rabbit dorsal root ganglion neurones in vitro. Journal of Lipid Research 33, 1677-1688.

Hanlon, C. S. \& Rubinsztein, D. C. (1995). Arginine residues at codons 112 and 158 in the Apolipoprotein E gene correspond to the ancestral state in humans. Atherosclerosis 112, 85-90.

Havel, R. J. \& Kane, J.P. (1989). Introduction: structure and metabolism of plasma lipoproteins. In the Metabolic Basis of Inherited Disease (ed. C. R. Scriver, A. L. Beaudet, W. S. Sly and D. Valle), pp. 1129-1138. McGraw-Hill: New York.

Houlston, R. S., Snowden, C., Green, F., Alberti, K. G. M. M. \& Humphries, S. E. (1989). Apolipoprotein (apo) E genotypes by polymerase chain reaction and allele-specific oligonucleotide probes: no detectable linkage disequilibrium between apo $\mathrm{E}$ and apo CII. Human Genetics 83, 364-368.

Mahley, R. W. (1988). Apolipoprotein E: cholesterol transport protein with expanding role in cell biology. Science 240, 622-630.

Mahley, R. W., Innerarity, T. L., Rall, S. C. Jr., Weisgraber, K. H. \& Taylor, J. M. (1990). Apolipoprotein E: genetic variants provide insights into its structure and function. Current Opinion in Lipidology 1, 87-95.

Mullan, M. \& Crawford, F. (1993). Genetic and molecular advances in Alzheimer's disease. Trends in Neurosciences 16, 398-403.
Namba, Y., Tomonaga, M., Kawasaki, H., Otomo, E. \& Ikeda, K. (1991). Apolipoprotein $\mathrm{E}$ immunoreactivity in cerebral amyloid deposits and neurofibrillary tangles in Alzheimer's disease and kuru plaque amyloid in Creutzfeldt-Jakob disease. Brain Research 541, 163-166.

Nathan, B. P., Bellosta, S., Sanan, D. A., Weisgraber, K. H., Mahley, R. W. \& Pitas, R. E. (1994). Differential effects of apolipoproteins E3 and E4 on neuronal growth in vitro. Science 264, 850-852.

Noguchi, S., Murakami, K. \& Yamada, N. (1993). Apolipoprotein E genotype and Alzheimer's disease. Lancet 342, 737.

Okuizumi, K., Onodera, O., Tanaka, H., Koboyashi, H., Tsuji, S. Takahashi, H., Oyanagi, K., Seki, K., Tanaka, M., Naruse, S. Miyatake, T., Mizusawa, H. \& Kanazawa, 1. (1994). ApoE- 64 and early-onset-Alzheimer's. Nature Genetics 7, 10-11.

Pericak-Vance, M. A., Bebout, J. L., Gaskell, P. C. Jr., Yamaoka L. A., Hung, W.-Y., Alberts, M. J., Walker, A. P., Bartlett, R. J., Haynes, C. A., Welsh, K. A., Earl, N. J., Heyman, A., Clark, C. M. \& Roses, A. D. (1991). Linkage studies in familial Alzheimer disease: evidence for chromosome 19 linkage. American Journal of Human Genetics 48, 1034-1050.

Plump, A. S., Smith, J. D., Hayek, T., Aalto-Setala, Walsh, A. Verstuyft, J. G., Rubin, E. M. \& Breslow, J. L. (1992). Severe hypercholesterolemia and atherosclerosis in apolipoprotein Edeficient mice created by homologous recombination in ES cells. Cell 71, 343-353.

Poirier, J., Hess, M., May, P. C. \& Finch, C. E. (1991). Astrocytic polipoprotein E mRNA and GFAP mRNA in hippocampus after entorhinal cortex lesioning. Molecular Brain Research 11, 97-106.

Poirier, J., Davignon, J., Bouthellier, D., Kogan, S., Bertrand, P. \& Gauthier, S. (1993). Apolipoprotein E polymorphism in Alzheimer's disease. Lancet 342, 697-699.

Popko, B., Goodrum, J. F., Bouldin, T. W., Zhang, S. H. \& Maeda, N. (1993). Nerve regeneration occurs in the absence of apolipoprotein E in mice. Journal of Neurochemistry 60, 1155-1158.

Rubinsztein, D. C., Hanlon, C. S., lrving, R. M., Goodburn, S. Evans, D. G., Kellar-Wood, H., Xuereb, J. H., Bandmann, O. \& Harding, A. E. (1994). Apo E genotypes in multiple sclerosis Parkinson's disease, schwannomas and late-onset Alzheimer's disease. Molecular and Cellular Probes 8, 519-526.

St. George-Hyslop, P., Crapper McLachlan, D., Tuda, T., Rogaev, E., Karlinsky, H., Lippa, C. F. \& Pollen, D. (1994). Alzheimer's disease and possible gene interaction. Science 263, 537.

Schellenberg, G. D., Deeb, S. S., Boehnke, M. L., Bryant, E. M., Martin, G. M., Lampe, T. H. \& Bird, T. D. (1987). Association of an apolipoprotein CII allele with familial dementia of the alzheimer type. Journal of Neurogenetics 4, 97-108

Schellenberg, G. D., Boehnke, M., Wijsman, E. M., Moore, D. K. Martin, G. M. \& Bird, T. D. (1992). Genetic association and linkage analysis of the apolipoprotein CII locus and familial Alzheimer's disease. Annals of Neurology 31, 223-227.

Schellenberg, G. D., Payami, H., Wijsman, E. M., Orr, H. T., Goddard, K. A. B., Anderson, L., Nemens, E., White, J. A., Alonso, M. E., Ball, M. J., Kaye, J., Morris, J. C., Chui, H., Sadovnick, D., Heston, L. L., Martin, G. M. \& Bird, T. D. (1993) Chromosome 14 and late-onset familial Alzheimer's disease (FAD). American Journal of Human Genetics 53, 619-628.

Shimano, H., Ishibashi, S., Murase, T., Gotohda, T., Yamada, N., Takaku, F. \& Ohtomo, E. (1989). Plasma apolipoproteins in patients with multi-infarct dementia. Atherosclerosis 79, 257-260

Skene, J. H. P. \& Shooter, E. M. (1983). Denervated sheath cells secrete a new protein after injury. Proceedings of the National Academy of Sciences, USA 80, 4169-4173.

Schmechel, D. E., Saunders, A. M., Strittmatter, W. J., Crain, B. J., Hulette, C. M., Joo, S. H., Pericak-Vance, M. A., Goldgaber, D $\&$ Roses, A. D. (1993). Increased amyloid $\beta$-peptide deposition in cerebral cortex as a consequence of apolipoprotein $E$ genotype in late-onset Alzheimer disease. Proceedings of the National Academy of Sciences, USA 90, 9649-9653.

Strittmatter, W. J., Saunders, A. M., Smechel, D., Pericak-Vance, M., Enghild, J., Salvesen, G. S. \& Roses, A. D. (1993a). 
Apolipoprotein $\mathrm{E}$; high avidity binding to $\beta$-amyloid and increased frequency of type 4 allele in late-onset familial Alzheimer disease. Proceedings of the National Academy of Sciences, USA 90, 1977-1981.

Strittmatter, W. J., Weisgraber, K. H., Huang, D. Y., Dong, L.-M., Salvesen, G. S., Pericak-Vance, M., Schmechel, D., Saunders, A. M., Goldgaber, D. \& Roses, A. D. (1993b). Binding of human apolipoprotein $\mathrm{E}$ to synthetic amyloid $\beta$ peptide: isoform-specific effects and implications for late-onset Alzheimer disease. Proceedings of the National Academy of Sciences, USA 90, 8098-8102.

Strittmatter, W. J., Weisgraber, K. H., Goedert, M., Saunders, A. M., Huang, D., Corder, E. H., Dong, L. M., Jakes, R., Alberts, M. J., Gilbert, J. R., Han, S.-H., Hulette, C., Einstein, G., Schmechel, D. E., Pericak-Vance, M. A. \& Roses, A. D. (1994). Hypothesis: microtubule instability and paired helical filament formation in the Alzheimer disease brain are related to apoliprotein E genotype. Experimental Neurology 125, 163-171.

Swanson, L. W., Simmon, D. M., Hoffman, S. L., Goldstein, J. L. \& Brown, M.S. (1988). Localisation of mRNA for low density lipoprotein receptor and a cholesterol synthetic enzyme in rabbit nervous system by in situ hybridization. Proceedings of the National Academy of Sciences, USA 85, 9821-9825.

van Duijn, C. M., de Knijff, P., Cruts, M., Wehnert, A., Havekes, L. M., Hofman, A. \& Van Broekhoven, C. (1994). Apolipoprotein E4 allele in a population-based study of early-onset Alzheimer's disease. Nature Genetics 7, 74-78.

Weintraub, M. S., Eisenberg, S. \& Breslow, J. L. (1987). Dietary fat clearance in normal subjects is regulated by genetic variation in apolipoprotein E. Journal of Clinical Investigation 80, 1571-1577.

Wilson, C., Wardell, M. R., Weisgraber, K. H., Mahley, R. W. \& Agard, D. A. (1991). Three-dimensional structure of the LDL receptor-binding domain of human apolipoprotein E. Science 252, 1817-1822.

Wisniewski, T. \& Frangione, B. (1992). Apolipoprotein E: a pathological chaperone protein in patients with cerebral and systemic amyloid. Neuroscience Letters 135, 235-238.

Wisniewski, T., Golabek, A., Matsabara, E., Ghiso, J. \& Frangione, B. (1993). Apolipoprotein E: Binding to soluble Alzheimer's $\beta$ amyloid. Biochemical and Biophysical Research Communications 192, 359-365. 